\title{
Crop Evaluation System Optimization: Attribute Weights Determination Based on Rough Sets Theory
}

\author{
Ruihong Wang, ${ }^{1}$ Liguo Zhang, ${ }^{1}$ and Xiuying $\mathrm{Lu}^{2}$ \\ ${ }^{1}$ College of Information Science \& Technology, Agricultural University of Hebei, Baoding, China \\ ${ }^{2}$ Agricultural University of Hebei, Baoding, China \\ Correspondence should be addressed to Ruihong Wang; xxwrh@hebau.edu.cn
}

Received 31 March 2017; Revised 9 July 2017; Accepted 15 August 2017; Published 14 September 2017

Academic Editor: Alessandro Lo Schiavo

Copyright (c) 2017 Ruihong Wang et al. This is an open access article distributed under the Creative Commons Attribution License, which permits unrestricted use, distribution, and reproduction in any medium, provided the original work is properly cited.

\begin{abstract}
The present study is mainly a continuation of our previous study, which is about a crop evaluation system development that is based on grey relational analysis. In that system, the attribute weight determination affects the evaluation result directly. Attribute weight is usually ascertained by decision-makers experience knowledge. In this paper, we utilize rough sets theory to calculate attribute significance and then combine it with weight given by decision-maker. This method is a comprehensive consideration of subjective experience knowledge and objective situation; thus it can acquire much more ideal results. Finally, based on this method, we improve the system based on ASP.NET technology.
\end{abstract}

\section{Introduction}

Since Ju-Long proposed grey relational system in 1982 [1, 2], scholars have employed this theory making a lot of research works [3-6]. In the agricultural industry, $\mathrm{Ma}$ et al. utilize it to evaluate new self-cultivated sugarcane lines, Yan and Shen evaluate carding cashmere fiber and Zhang et al. evaluate new watermelon varieties [7-9]. Based on these previous works, we have developed a crop evaluation system based on grey relational analysis (GRA) [10]. The experiment results showed that the crop evaluation system is effective and could greatly improve the work efficiency of the researcher and expand the application scope. When we exploit GRA method to evaluate crops, attribute weight ascertainment plays an important role, because it affects the evaluation result directly.

In the management of multiple attribute decision-making system, people often take multiple indexes as evaluation standard for alternative scheme filtration. In the process of evaluation and decision-making, attribute weight is essential. It reflects the status or role of various factors and directly affects the final judgment and decision-making. We usually ascertain attribute weight based on the importance of each attribute. There are lots of classic decision methods, that is,
AHP, TOPSIS, ELECTRE, and so forth [11, 12]. Although those methods promote the development of decision theory, the attribute weight is generally given by experts [10]. Potential uncertainty in expert judgment is the main disadvantage of the subjective methods. The weight determination is much affected by expert experience knowledge and sometimes is not able to objectively reflect the actual situation and even can distort the judgment and decision result [13].

In 1982, professor Pawlak proposed a theory of rough sets [14], which provides a formal tool for dealing with imprecise or incomplete information. Since its introduction, the theory has generated a great deal of interest along researchers [1517], as well as among researchers dealing with machine learning and knowledge acquisition for expert systems [1822]. It is used for knowledge acquisition and analysis without providing any a priori information and fully reflects the objectivity of data.

This paper presents a new method to determine attribute weights based on the theory of rough sets. First, objective weight value is derived by significance in the theory of rough sets [23-27]. And then, according to practical application background, we combine objective weight with subjective weight determined by expert experience knowledge and 
ascertain the final weight value so as to realize reasonable unification of subjective prior knowledge and objective situation. Finally, we utilize ASP.NET programming language to improve the crop evaluation system.

In this paper, first, in Section 2, we present preliminary and notation of the theory of rough sets. Section 3 is the algorithm of attribute weight determination. Section 4 is the real example in Fuji apple evaluation. In Section 5, we utilize ASP.NET to improve the system.

\section{Methods}

2.1. Theory of Rough Sets. The notion of equivalence is introduced first. $R$ is the equivalence relation defined on $U$, where $U$ is the universe of objects. A binary relation $R \subseteq$ $X \times Y$ which is reflexive (i.e., an object is in relation with itself, $x R x$ ), symmetric (if $x R y$, then $y R x$ ), and transitive (if $x R y$ and $y R z$, then $x R z)$ is called an equivalence relation [28]. $X \subset U$ is a subset of $U .[x]_{R}$ is the equivalence class generated by equivalence relation $R$. The equivalence class of an element $x \in X$ consists of all objects $y \in X$ such that $x R y$. Let $A=(U, A)$ be an information system and let $R \subseteq A$ and $X \subseteq U$. We can approximate $X$ using only the information contained in $R$ by constructing the $R$-lower and $R$-upper approximations of $X$, denoted as $R_{-}(X)$ and $R^{-}(X)$, respectively, where $R_{-}(X)=\left\{x \in U \mid[x]_{R} \subset X\right\}$ and $R^{-}(X)=\left\{x \in U \mid[x]_{R} \cap X \neq \phi\right\}$. The objects in $R_{-}(X)$ can be with certainty classified as members of $X$ on the basis of knowledge in $R$, where the objects in $R^{-}(X)$ can be only classified as possible members of $X$ on the basis of knowledge in $R$. If $R_{-}(X) \neq R^{-}(X)$, set $X$ is said to be rough.

2.2. Information System. Let $S=(U, A, V, f)$ be an information system such that $U$ denotes a nonempty finite set of objects, called universe. $A=C \cup D$ is attribute set; subsets $C$ and $D$ are called condition attribute set and decision attribute set, respectively. $V=\bigcup_{a \in A} V_{a}$ are the sets of attribute value. $f: U \times A \rightarrow V$ is information function, which specifies the attribute value of object $x$ of set $U$. With any subsets $B \subseteq A$, there is an associated equivalence relation $\operatorname{IND}_{A}(B)$ :

$$
\begin{aligned}
& \operatorname{IND}_{A}(B) \\
& \quad=\left\{(x, y) \mid(x, y) \in U^{2}, \forall a \in B, f(x, a)=f(y, a)\right\} .
\end{aligned}
$$

$\operatorname{IND}_{A}(B)$ is called $B$-indiscernibility relation and the subscript $A$ is usually omitted if it is clear which information system is meant. $\operatorname{IND}(B)=\bigcap_{b \in B} \operatorname{IND}(\{b\})$ is obvious. The equivalence relation $\operatorname{IND}(B)$ constitutes the partition of $U$, denoted by $U / \operatorname{IND}(B)$ and often abbreviated to $U / B$.

2.3. Attribute Significance. In this section, we will introduce basic definition of attribute significance [29-31]. We utilize the attribute reduction method of the theory of rough sets to ascertain each attribute's significance. Using attribute reduction, we find core attribute and reduce unnecessary attribute and determine the important relation between attributes. On the other hand, after reducing one attribute, we define attribute contribution degree through judging the variation size of system structure. The bigger the variation size is, the greater the attribute weight is.

In an information system, we define $\operatorname{Sig}_{B}(a)$ as attribute $a$ significant for subset $B$ :

$$
\operatorname{Sig}_{B}(a)=1-\frac{|B \cup\{a\}|}{|B|},
$$

where $|B|=|\operatorname{IND}(B)|$; set $U / \operatorname{IND}(B)=U / B=\left\{X_{1}, X_{2}\right.$, $\left.\ldots, X_{n}\right\}$; then $|B|=\sum_{i=1}^{n} \sum\left|X_{i}\right|^{2}$.

In practice, when we apply formula (2) to calculate the contribution degree, we may encounter this situation: some attribute contribution degrees are 0 or have same values, which do not accord with facts. In order to solve this problem, we define the improvement significance formula.

$$
\begin{aligned}
\operatorname{Sig}_{B_{i}}^{\prime} & =\mid \operatorname{Sig}_{B_{i}}\left(b_{i}\right) \\
& -\frac{1}{n-1} \sum_{j=1(j \neq i)}^{n}\left[\frac{\operatorname{Sig}_{B_{i, j}}\left(b_{i}, b_{j}\right)-\operatorname{Sig}_{B_{i}}\left(b_{i}\right)}{2}\right] \mid,
\end{aligned}
$$

where $B \subseteq C$ is subset of attribute set $C, B=\left\{b_{1}, b_{2}, \ldots, b_{n}\right\}, b_{i}$ is an attribute, $B_{i}=B-\left\{b_{i}\right\}$, and $B_{i, j}=B-\left\{b_{i}, b_{j}\right\}$.

\section{Attribute Weight Ascertainment}

We carry out the normalization processing of attribute significance to obtain the objective weight (OW) of each attribute. The calculation formulas, respectively, corresponding to formulas (2) and (3) are as follows:

$$
\begin{aligned}
\operatorname{OW}\left(a_{i}\right) & =\frac{\operatorname{Sig}_{B}\left(a_{i}\right)}{\sum_{i=1}^{n} \operatorname{Sig}_{B}\left(a_{i}\right)}, \\
\operatorname{OW}^{\prime}\left(a_{i}\right) & =\frac{\operatorname{Sig}_{B}^{\prime}\left(a_{i}\right)}{\sum_{i=1}^{n} \operatorname{Sig}_{B}^{\prime}\left(a_{i}\right)} .
\end{aligned}
$$

Then combine the subjective weight (SW) and OW to get the final weight $(\mathrm{FW})$ formula as follows:

$$
\mathrm{FW}\left(a_{i}\right)=(1-\lambda) \mathrm{OW}\left(a_{i}\right)+\lambda \mathrm{SW}\left(a_{i}\right),
$$

where $\lambda \in(0,1)$ is constant.

\section{The Analysis of Influence Factors in Fuji Apple}

In order to verify the effectiveness of weight acquisition method, we still adopt the previous paper's data for comprehensive evaluation: Fuji apple evaluation data [7] are shown in Table 1. Before analysis, we need to discrete the data according to the following method. First, calculate each attribute value interval as approximate distribution interval; then, set ideal variety data as objective value and suppose it has $5 \%$ fluctuation in random distribution interval; finally, judge whether each attribute value falls into ideal value interval and then assign discrete value of 1 or 0 , respectively, 


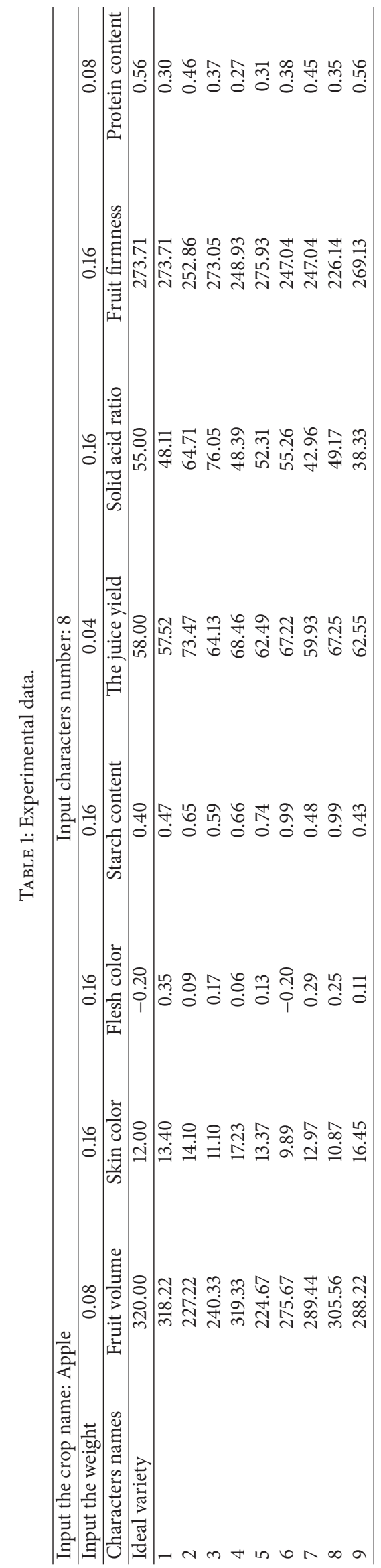


TABle 2: Decision table.

\begin{tabular}{lllllllll}
\hline$U$ & $a$ & $b$ & $c$ & $d$ & $e$ & $f$ & $g$ & $h$ \\
\hline 1 & 1 & 0 & 0 & 0 & 1 & 0 & 1 & 0 \\
2 & 0 & 0 & 0 & 0 & 0 & 0 & 0 & 0 \\
3 & 0 & 0 & 0 & 0 & 0 & 0 & 1 & 0 \\
4 & 1 & 0 & 0 & 0 & 0 & 0 & 0 & 0 \\
5 & 0 & 0 & 0 & 0 & 0 & 0 & 1 & 0 \\
6 & 0 & 0 & 1 & 0 & 0 & 1 & 0 & 0 \\
7 & 0 & 0 & 0 & 0 & 0 & 0 & 0 & 0 \\
8 & 0 & 0 & 0 & 0 & 0 & 0 & 0 & 1 \\
9 & 0 & 0 & 0 & 1 & 0 & 0 & 0 & 0 \\
\hline
\end{tabular}

and establish the decision table $T=\langle U, C\rangle$, as shown in Table 2, where $U=\{1,2,3,4,5,6,7,8,9\}$ and $C=$ $\{a, b, c, d, e, f, g, h\}$ corresponding to eight attributes.

Employing the method introduced in Section 2.3, we calculate attribute significance. Set $C_{1}=\{b, c, d, e, f, g, h\}$, $\ldots, C_{8}=\{a, b, c, d, e, f, g\}$.

According to equivalence relation, we gain

$$
\begin{aligned}
& \operatorname{IND}(C)=\{\{1\},\{2,7,8\},\{3,5\},\{4\},\{6\},\{9\}\} ; \\
& \operatorname{IND}\left(C_{1}\right)=\{\{1\},\{2,4,7,8\},\{3,5\},\{6\},\{9\}\} ; \\
& \operatorname{IND}\left(C_{2}\right)=\{\{1\},\{2,7,8\},\{3,5\},\{4\},\{6\},\{9\}\} ; \\
& \operatorname{IND}\left(C_{3}\right)=\{\{1\},\{2,7,8\},\{3,5\},\{4\},\{6\},\{9\}\} ; \\
& \operatorname{IND}\left(C_{4}\right)=\{\{1\},\{2,7,8\},\{3,5\},\{4\},\{6\},\{9\}\} ; \\
& \operatorname{IND}\left(C_{5}\right)=\{\{1\},\{2,7,8\},\{3,5\},\{4\},\{6\},\{9\}\} ; \\
& \operatorname{IND}\left(C_{6}\right)=\{\{1\},\{2,7,8\},\{3,5\},\{4\},\{6\},\{9\}\} ; \\
& \operatorname{IND}\left(C_{7}\right)=\{\{1\},\{2,3,5,7,8\},\{4\},\{6\},\{9\}\} ; \\
& \operatorname{IND}\left(C_{8}\right)=\{\{1\},\{2,7,8\},\{3,5\},\{4\},\{6\},\{9\}\} .
\end{aligned}
$$

According to formula (2), we calculate attribute significance:

$$
\begin{aligned}
\operatorname{Sig}_{C_{1}}(a) & =\frac{6}{23}, \\
\operatorname{Sig}_{C_{2}}(b) & =\operatorname{Sig}_{C_{3}}(c)=\operatorname{Sig}_{C_{4}}(d)=\operatorname{Sig}_{C_{5}}(e) \\
& =\operatorname{Sig}_{C_{6}}(f)=\operatorname{Sig}_{C_{8}}(h)=0, \\
\operatorname{Sig}_{C_{7}}(g) & =\frac{12}{29} .
\end{aligned}
$$

Obviously, this result jibes with objective cognition. When we consume apples, we maybe focus on the intuitive attributes " $a$ " and $g$ to evaluate them. But significance of attributes " $b$," "cc," " $d$," "e," " $f$," and " $h$ " is 0 ; the result is not scientific, so we employ formula (3) to calculate significance. Let

$$
\begin{aligned}
& C_{(a, b)}=\{c, d, e, f, g, h\}, \ldots, C_{(a, h)}=\{b, c, d, e, f, g\}, \\
& \frac{U}{C_{(a, b)}}=\{\{1\},\{2,4,7,8\},\{3,5\},\{6\},\{9\}\}, \\
& \frac{U}{C_{(a, c)}}=\{\{1\},\{2,4,7,8\},\{3,5\},\{6\},\{9\}\}, \\
& \frac{U}{C_{(a, d)}}=\{\{1\},\{2,4,7,8\},\{3,5\},\{6\},\{9\}\}, \\
& \frac{U}{C_{(a, e)}}=\{\{1,3,5\},\{2,4,7,8\},\{6\},\{9\}\}, \\
& \frac{U}{C_{(a, f)}}=\{\{1\},\{2,4,7,8\},\{3,5\},\{6\},\{9\}\}, \\
& \frac{U}{C_{(a, g)}}=\{\{1\},\{2,3,4,5,7,8\},\{6\},\{9\}\}, \\
& \frac{U}{C_{(a, h)}}=\{\{1\},\{2,4,7,8\},\{3,5\},\{6\},\{9\}\} .
\end{aligned}
$$
result:

According to formula (2), we can acquire the following

$$
\begin{aligned}
& \operatorname{Sig}_{C_{(a, b)}}(a, b)=\frac{6}{23}, \\
& \operatorname{Sig}_{C_{(a, c)}}(a, c)=\frac{6}{23}, \\
& \operatorname{Sig}_{C_{(a, d)}}(a, d)=\frac{6}{23}, \\
& \operatorname{Sig}_{C_{(a, e)}}(a, e)=\frac{10}{27}, \\
& \operatorname{Sig}_{C_{(a, f)}(a, f)}=\frac{6}{23},
\end{aligned}
$$




$$
\begin{aligned}
& \operatorname{Sig}_{C_{(a, g)}}(a, g)=\frac{22}{39}, \\
& \operatorname{Sig}_{C_{(a, h)}}(a, h)=\frac{6}{23} .
\end{aligned}
$$

Then we plug the above result into formula (3); we calculate the improvement significance of attribute $a$ :

$$
\begin{aligned}
& \operatorname{Sig}_{C_{1}}^{\prime}(a) \\
& \quad=\left|\operatorname{Sig}_{C_{1}}(a)-\frac{1}{7} \sum_{i=b}^{h}\left(\frac{\operatorname{Sig}_{C_{(a, i)}}(a, i)-\operatorname{Sig}_{C_{1}}(a)}{2}\right)\right| \\
& =0.2314 .
\end{aligned}
$$
cance:

By the same procedure, we gain another attribute signifi-

$$
\begin{aligned}
& \operatorname{Sig}_{C_{2}}^{\prime}(b)=0.0482, \\
& \operatorname{Sig}_{C_{3}}^{\prime}(c)=0.0668, \\
& \operatorname{Sig}_{C_{4}}^{\prime}(d)=0.0668, \\
& \operatorname{Sig}_{C_{5}}^{\prime}(e)=0.0587, \\
& \operatorname{Sig}_{C_{6}}^{\prime}(f)=0.0668, \\
& \operatorname{Sig}_{C_{7}}^{\prime}(g)=0.4004, \\
& \operatorname{Sig}_{C_{8}}^{\prime}(h)=0.0668 .
\end{aligned}
$$

According to formula (5), we normalize the above value to get each attribute's OW:

$$
\begin{aligned}
& \mathrm{OW}(a)=0.2300, \\
& \mathrm{OW}(b)=0.0480, \\
& \mathrm{OW}(c)=0.0664, \\
& \mathrm{OW}(d)=0.0664, \\
& \mathrm{OW}(e)=0.0584, \\
& \mathrm{OW}(f)=0.0664, \\
& \mathrm{OW}(g)=0.3980, \\
& \mathrm{OW}(h)=0.0664 .
\end{aligned}
$$

Then, combine the SW and OW to get the FW; suppose $\lambda=$ 0.8 :

$$
\begin{aligned}
& \mathrm{FW}(a)=0.11, \\
& \mathrm{FW}(b)=0.14, \\
& \mathrm{FW}(c)=0.14, \\
& \mathrm{FW}(d)=0.14, \\
& \mathrm{FW}(e)=0.04, \\
& \mathrm{FW}(f)=0.14, \\
& \mathrm{FW}(g)=0.21, \\
& \mathrm{FW}(h)=0.08
\end{aligned}
$$

In the calculation of the subjective weight, we not only consider the internal relations of factors but also avoid situations where the attribute weight is 0 . Therefore, it is a good method to determine the weight of single attribute by means of the importance of single attribute and the importance of combination attributes.

In the previous paper, attribute weight is ascertained by decision-makers experience knowledge. Since individual architectonic knowledge is different, results vary with each individual. Compared with the previous paper, the result by the proposed method is more reasonable [29].

Rescale the parameter value to obtain different FW.

\section{Crop Evaluation System Optimization}

We utilize C\# programming language to improve the system and add two input boxes: floating rate and value of $\lambda$. The former determines OW; the latter determines proportion of $\mathrm{OW}$ and SW in FW. Set $\lambda=1$; FW equals SW; the curve is the same as previous paper, shown in Figure 1 . Set $\lambda=0.8$ to get different curve. The result is in accord with conclusion produced in Section 4, shown in Figure 2.

\section{Conclusion}

Utilizing attribute significance concept, the present paper introduces a new weight ascertainment method. It overcomes former method deficiency that attribute weight determination relies too much on expert experience knowledge. Since individual architectonic knowledge is different, results vary with each individual. By adding objective attribute weight, decisions makers can combine own interests and specific application to choose the appropriate performance coefficient adjustment of subjective weight and objective weight ratio, making the evaluation result more reasonable. Finally, we utilize C\# programming language to improve the system, which is more convenient for agricultural researchers to employ.

\section{Conflicts of Interest}

The authors declare that they have no conflicts of interest. 
Relational degree analysis between each variety and ideal variety

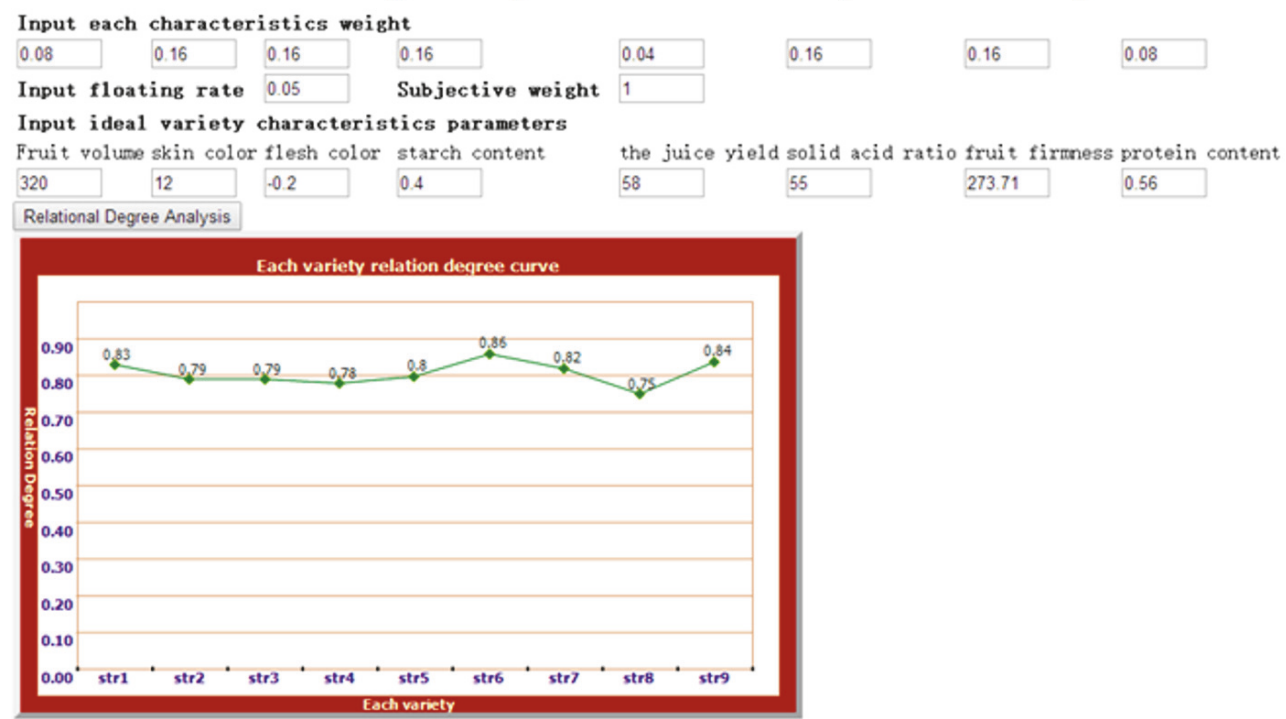

Figure 1: Original curve.

Relational degree analysis between each variety and ideal variety

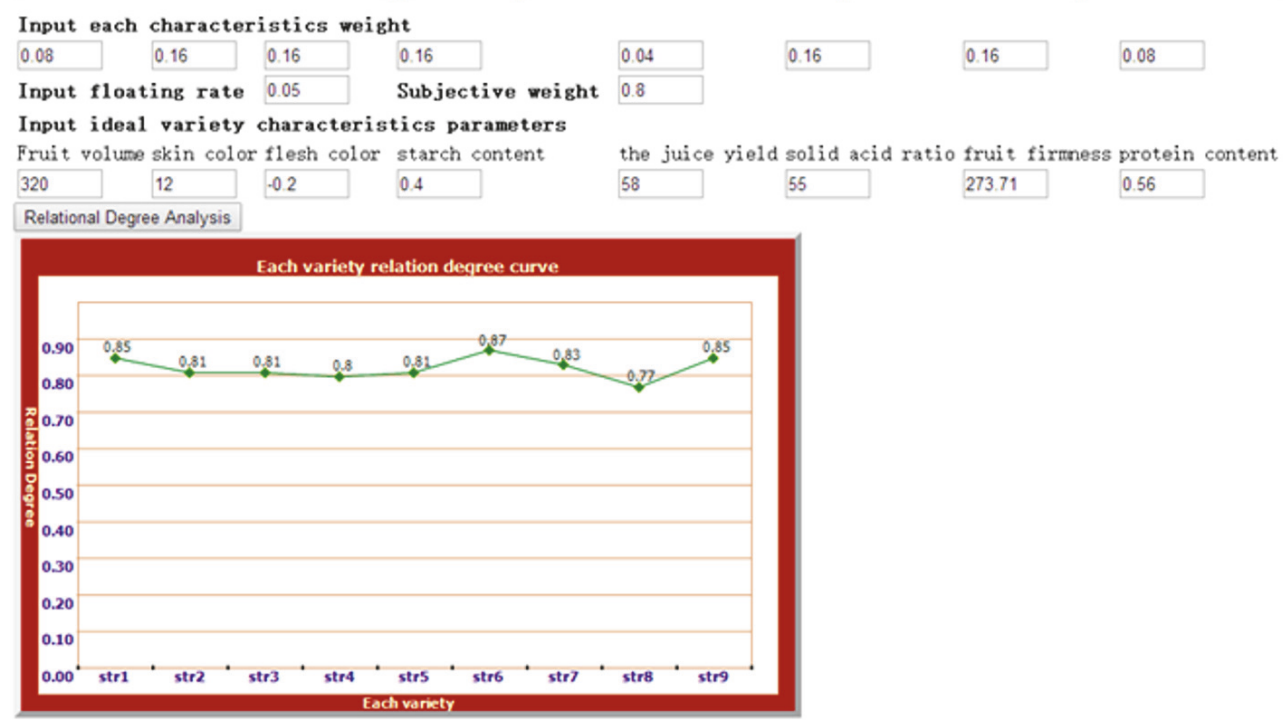

FIGURE 2: Improving curve.

\section{Acknowledgments}

This work was supported by Science and Technology Plan Projects of Hebei Province (nos. 15210138 and 15ZN010).

\section{References}

[1] D. Ju-Long, "Control problems of grey systems," Systems and Control Letters, vol. 1, no. 5, pp. 288-294, 1982.

[2] D. Ju-Long, “The grey control system," Journal Huazhong Central China University of Science and Tedimelogy, vol. 10, no. 3, pp. 9-18, 1982.
[3] Y. Kuo, T. Yang, and G.-W. Huang, "The use of grey relational analysis in solving multiple attribute decision-making problems," Computers and Industrial Engineering, vol. 55, no. 1, pp. 80-93, 2008.

[4] N. Tosun, "Determination of optimum parameters for multiperformance characteristics in drilling by using grey relational analysis," International Journal of Advanced Manufacturing Technology, vol. 28, no. 5-6, pp. 450-455, 2006.

[5] J. W. K. Chan and T. K. L. Tong, "Multi-criteria material selections and end-of-life product strategy: grey relational analysis approach," Materials Design, vol. 28, no. 5, pp. 15391546, 2007. 
[6] C. L. Lin, "Use of the Taguchi method and grey relational analysis to optimize turning operations with multiple performance characteristics," Materials and Manufacturing Processes, vol. 19, no. 2, pp. 209-220, 2004.

[7] W. Ma, Q. Guo, C. Wei et al., "Comprehensive evaluation of new self-cultivated sugarcane lines by grey relational analysis," Asian Agricultural Research, vol. 6, no. 9, pp. 85-88, 2014.

[8] X.-F. Yan and Y. Shen, "Comprehensive quality evaluation of dehaired cashmere fiber based on grey relational analysis," Wool Textile Journal, vol. 42, no. 11, pp. 46-50, 2014.

[9] X. Zhang, Z. Wu et al., "Grey correlation multidimensional comprehensive evaluation of new watermelon varieties," Journal of Shanxi Agricultural Sciences, 2014.

[10] R. Wang, L. Zhang, L. Dong, and X. Lu, "The development and application of crop evaluation system based on gra," Mathematical Problems in Engineering, vol. 2016, no. 9, Article ID 1815240, pp. 1-6, 2016.

[11] D. Chang, "Applications of the extent analysis method on fuzzy AHP," European Journal of Operational Research, vol. 95, no. 3, pp. 649-655, 1996.

[12] C. Chen, "Extensions of the TOPSIS for group decision-making under fuzzy environment," Fuzzy Sets and Systems, vol. 114, no. 1, pp. 1-9, 2000.

[13] M. Alemi-Ardakani, A. S. Milani, S. Yannacopoulos, and G. Shokouhi, "On the effect of subjective, objective and combinative weighting in multiple criteria decision making: A case study on impact optimization of composites," Expert Systems with Applications, vol. 46, pp. 426-438, 2016.

[14] Z. Pawlak, "Rough sets," International Journal of Computer and Information Sciences, vol. 11, no. 5, pp. 341-356, 1982.

[15] H. Rasiowa, "Rough concepts and multiple valued logic," in Proceedings of 16th International Symposium on Multiple Valued Logic, pp. 228-288, New York, NY, USA, 1986.

[16] H. Rasiowa and G. Epstein, "Approximation reasoning and Scott's information systems," in International Symposium on Methodologies for Intelligent Systems, North Holland, Amsterdam, 1987.

[17] A. Wasilewska, "Syntactic decision procedures in information systems," International Journal of Man-Machine Studies, vol. 30, no. 3, pp. 273-285, 1989.

[18] A. Mrozek, "Rough sets and some aspects of expert system realization," in Proceedings of the 7th International Workshop on Expert Systems, pp. 587-611, Avignon, France, 1987.

[19] J. W. Grzymala-Busse, "Knowledge acquisition under uncertainty - a rough set approach," Journal of Intelligent and Robotic Systems, vol. 1, no. 1, pp. 3-16, 1988.

[20] Z. Pawlak, K. Slowinski, and R. Slowinski, "Rough classification of patients after highly selective vagotomy for duodenal ulcer," International Journal of Man-Machine Studies, vol. 24, no. 5, pp. 413-433, 1986.

[21] P. Hajdo, T. Arciszewski, W. Ziarko, and H. Aktan, "Inductive shallow approach for generation of engineering models," in Proceedings of the 9th European Meeting on Cybernetics, and Systems Research, pp. 933-940, Vienna, Austria, 1988.

[22] W. Ziark and J. Katzberg, "Control algorithm acquisition, analysis and reduction: A machine learning approach," in KnowledgeBased System Diagnosis, Supervision and Control, Plenum, pp. 167-178, Springer US, New York, NY, USA, 1989.

[23] L. Dun, H. Pei, and C. Jiang, "New methodology of attribute weights acquisition based on rough sets theory," Systems Engineering and Electronics, vol. 30, no. 8, pp. 1481-1484, 2008.
[24] J. Wu, C.-Y. Liang, and W.-N. Li, "Method to determine attribute weights based on subjective and objective integrated," Systems Engineering and Electronics, vol. 29, no. 3, pp. 383-387, 2007.

[25] H. Guan and D. Tian, "Rule abstracting algorithm by decision tree based on the importance of attribute," Systems Engineering and Electronics, vol. 3, pp. 334-337, 2004.

[26] K.-L. Wen and S.-K. Changchien, "The weighting analysis of influence factors in gas breakdown via rough set and $\mathrm{GM}(\mathrm{h}, \mathrm{N})$," Journal of Computers, vol. 3, no. 11, pp. 17-24, 2008.

[27] H. Y. Liang, Y. T. Lee, M. L. You, and K. L. Wen, "The weighting analysis of influence factor in clinical skin physiology assessment via rough sets method," Journal of Bioscience and Biotechnology, vol. 2, no. 1, pp. 39-46, 2010.

[28] J. Komorowski, Z. Pawlak, L. Polkowski, and A. Skowron, "Rough sets: a tutorial," in Rough fuzzy hybridization, pp. 3-98, 1999.

[29] W. Li, D. Chen, and Y. Yang, "A new method to determination of attribute weightbased on rough sets," Journal of Guangdong University of Petrochemical Technology, vol. 22, no. 6, pp. 66-72, 2012.

[30] L. Sun and Z. An, "A new method to the determination of land grading factors' weight based on rough set," Science Technology and Engineering, vol. 13, no. 33, pp. 10098-10101, 2013.

[31] Z. Pawlak and R. Sowinski, "Rough set approach to multiattribute decision analysis," European Journal of Operational Research, vol. 72, no. 3, pp. 443-459, 1994. 


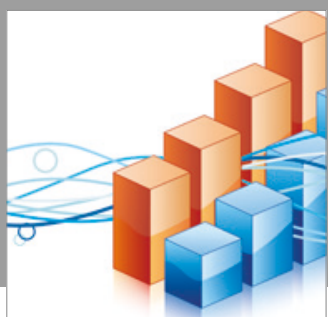

Advances in

Operations Research

vatersals

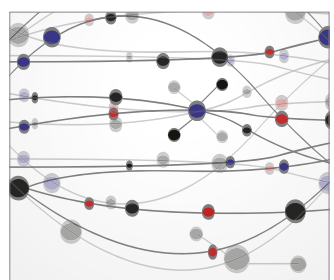

\section{The Scientific} World Journal
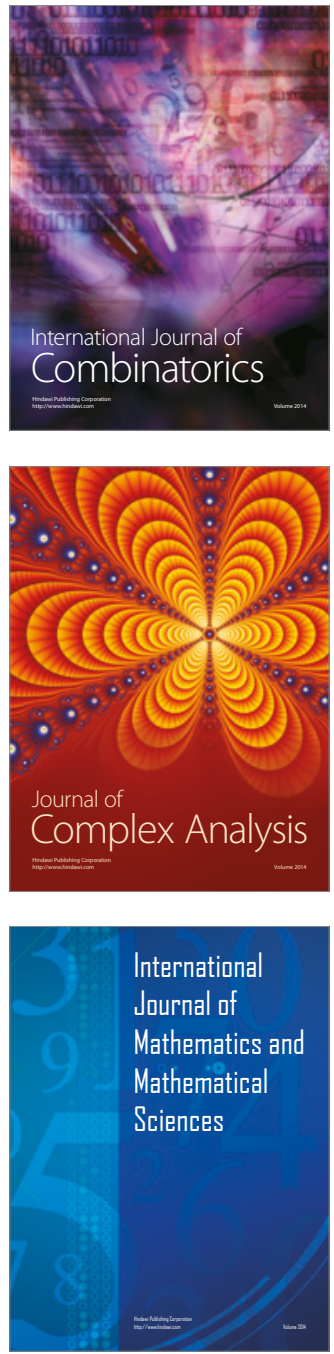
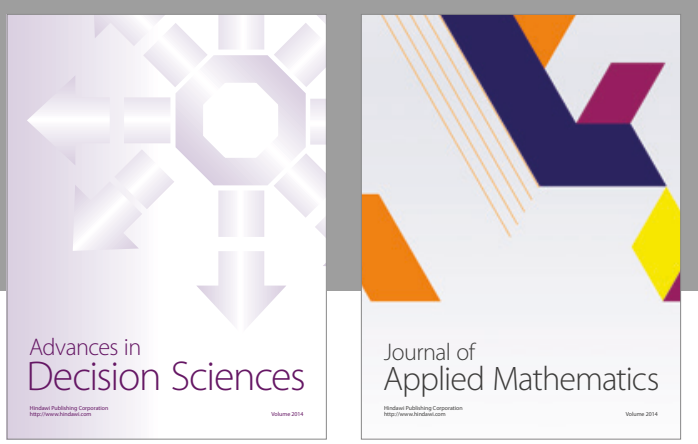

Algebra

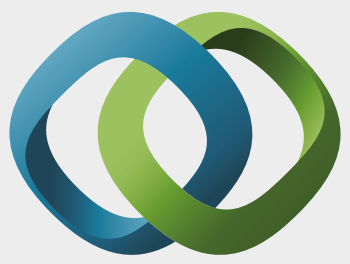

\section{Hindawi}

Submit your manuscripts at

https://www.hindawi.com
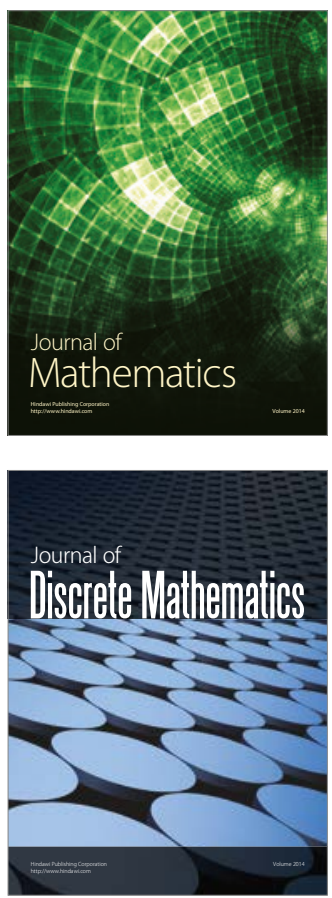

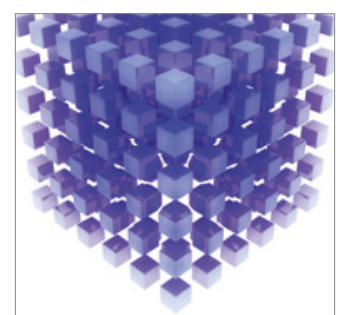

Mathematical Problems in Engineering
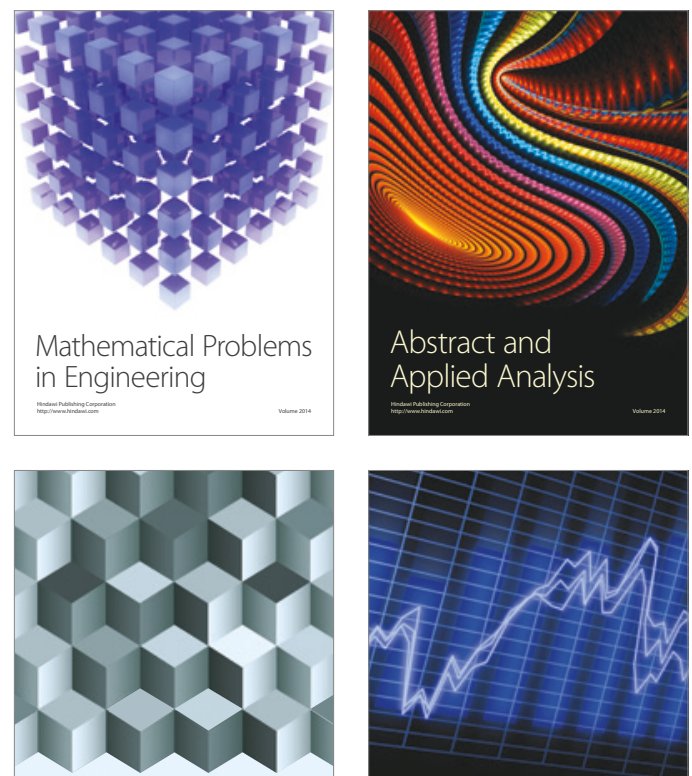

Journal of

Function Spaces

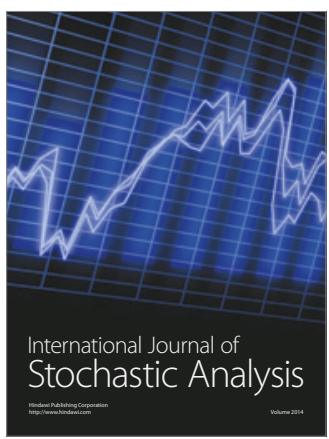

Probability and Statistics
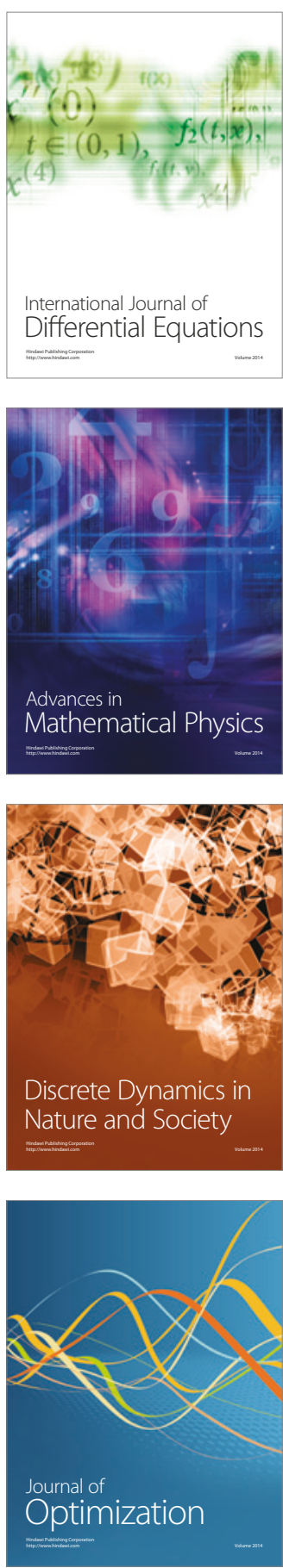